\title{
Speech Language Pathologists and Teachers Perceptions of Bilingual Students
}

\author{
Lauren Getzler ${ }^{1}$, Pauline LeMaster ${ }^{1}$ and Mark Emerick ${ }^{1}$ \\ ${ }^{1}$ Muhlenberg College, Allentown, PA, USA
}

\section{ABSTRACT}

Prior research has focused on speech language pathologists (SLPs) and teachers and their ability to work with bilingual students. It has been found that both teachers and SLPs struggle to work with bilingual students as they do not have the prior knowledge necessary to work efficiently with these students (Teoh, Brebner, \& McAllister, 2017). Additionally, speech therapy and other necessary resources for students to succeed may only be given in one language, potentially not their L1, making it difficult for students and teachers to work in the L2 language (Hammond, Mitchell, \& Johnson, 2009). There has been a lack of research that has explored SLPs and the ways in which they treat and work with students who are bilingual and multilingual compared to those who are monolingual. Studying these groups simultaneously will provide information from different learning environments as well as give insight on the amount of or lack of one-on-one attention given to bilingual students in those respective environments. The purpose of this research is to understand how SLPs' and teachers perceive and work with students who are bilingual versus how they work with and perceive students who are monolingual. Results have shown that there is a significant difference in the level of preparedness of and in the perceptions that teachers and SLPs hold when it comes to working with students who are bilingual and multilingual.

\section{Introduction}

In a learning environment, there are many professionals who play meaningful roles in students' learning and engagement. These professionals include teachers and speech language pathologists (SLPs), both of whom work with students on a daily basis to prepare them for academic and future success. Teachers and SLPs work with students with a wide range of abilities, including those who have language and learning barriers. These professionals should understand the ways in which a student's culture, ethnicity, and language proficiency can impact the student's ability to perform academically in order to know how to best help that student succeed (Edl, Jones, \& Estell, 2008). Additionally, it is important that these professionals be aware of the perspectives and beliefs they may hold towards these students.

Teachers and SLPs work with students who are monolingual, bilingual, and multilingual, and because of the increasing cultural and linguistic diversity in the US, they are increasingly working with more and more bilingual individuals (De Lamo White \& Jin, 2011). Due to the increasing number of bilingual students, it is essential to remember that teacher and SLP perceptions can play a vital role in student performance and integration into the classroom community (Rizzuto, 2017). The misconceptions that SLPs and teachers hold are often reflective of the quality of their own educational experience in preparation to work with bilingual and multilingual students. Teachers and SLPs may not have the ability to properly educate students who are bilingual due to a lack of access to and guidance from previous research and experience. Teachers and SLPs often lack proper preparedness in how to work with bilingual and multilingual students even after completing their undergraduate and graduate programs (Hammer, Detwiler, Detwiler, Blood \& Qualls 2004). The perceptions that both teachers and SLPs may have towards bilingual students may directly impact the way in which they interact with and treat these students (Faroqi-Shah, Frymark, Mullen \& Wang, 2010). Although it is important to understand SLPs and Teachers beliefs about ELLs, very little research 
addresses this area, especially for SLPs. The purpose of this study is to understand how SLPs' and teachers perceive and work with students who are bilingual and multilingual versus how they work with and perceive students who are monolingual.

\section{Literature Review}

\section{Background Information}

The research on teachers' and SLPs' perceptions of and practices for working with bilingual and multilingual students is limited, therefore we are informing our discussion of perceptions with literature in teacher education, since those perceptions and practices shape students' experiences. As the demographics of the student population in the US are diverse and constantly changing, it is becoming more important for educators to be properly trained to work with these students, especially given the variety of their backgrounds and needs (Olvera, 2015). Research has consistently revealed a difference in the way that bilingual and monolingual students are educated and treated based on biases and misconceptions that both SLPs and teachers often hold. EL placement depends on state and school district assessments as well as on specific thresholds for each school, leading to an inconsistent and unreliable EL classroom placement (Umansky \& Dumont 2019). This can result in EL students being put in an unfair position from which teachers and SLPs may develop misconceptions.

\section{Teacher Preparedness and Perceptions}

Biases and preconceived notions about bilingual students are especially evident in schools when looking at the academic performance of these students compared to their monolingual peers. The perceptions that teachers hold shape the way that they perceive their role as educators (Rizzuto, 2017). If negative, it can affect the educational experience of bilingual students inside the classroom and even in life after school (Commins \& Miramontes, 1989). Hindering student success, although usually subconsciously, teacher perceptions can directly affect a bilingual student's participation and comfort level in the classroom. For example, Fitts and Gross (2012) found that there is a direct correlation between student academic performance and the level of support that they receive in the classroom, and the more unbiased the teacher perspective, the more likely it will be that all students will be supported. Ensuring that teachers are properly trained and educated before working with bilingual students would increase the likelihood that those students will thrive and succeed both inside and outside the classroom.

In one study, more than half of teachers expressed feeling like bilingual students were severely disadvantaged in terms of language accessibility (MacIntosh \& Ornstein, 1974). This bias held by teachers particularly affects Latino/a children, and revealed a belief that these students were not able to perform as well academically compared to their White peers (Han, 2012). Conversely, another study found that educators will begin to view students as more similar over time, meaning less focus on the preconceived notions about student differences (Edl, Jones, \& Estell, 2008). This bias negatively affects the way that teachers teach bilingual students and prevents these students from receiving a quality education. Biases that are held by educators are evident in their approaches to teaching bilingual students, primarily Latino/a students (De Lamo White \& Jin, 2011). Their perspective on language reflects experience with teaching primarily monolingual students, which is not effective in teaching bilingual students and therefore continues to put their bilingual students at a serious disadvantage (Palmer \& Martínez, 2013).

Although teachers may try to include culturally relevant pedagogy into their curriculum, many times, they are ill-prepared to do so. In classrooms across the United States, teachers tend to be White and female and many consider themselves race neutral or colorblind and therefore fail to support all of their students (Olvera, 2015). Most teachers have not had sufficient professional development and previous coursework relating to EL students, how they learn, and how to change curriculum for a mainstream classroom (Pérez Cañado, 2016). Comparatively, at times when 
teachers want to further support students in their native language, they may feel unable to do so since they cannot fully address the specific academic needs in their mainstream classroom due to the abundance of diverse backgrounds and demands of the class (Olvera, 2015). In mainstream classroom settings, with an increased amount of preparedness of working with bilingual students, teachers can provide one-on-one support to their students who need more assistance (Rizzuto, 2017). This individual attention provided to students increases the likelihood of their academic success as the teacher establishes themself as part of the students' support system.

\section{Student Performance and Classroom Experience}

In a classroom, it is important for a teacher to be prepared and willing to help all students; a lack of preparedness to work with bilingual students may impact these students' academic performance. In addition, teacher perceptions play an important role in student performance (Rizzuto, 2017). Umansky and Dumont (2019) found that teachers' perceptions can greatly affect student test scores and measures of intelligence. They also noted that negative perceptions and lack of preparation from teachers can affect the students achievement, course placement, behavioral outcomes, graduation, and post-secondary enrollment- showing that teachers' actions can affect students beyond the K-12 setting. Surprisingly, they discovered that many times, due to the EL classification, these students are placed in lower-level classes with less experienced teachers compared to their monolingual peers. This results in bilingual and multilingual students often being put into an unfair position--due to either a wrongful placement or the right placement with a teacher whose misconceptions could hinder the students' ability to succeed academically.

That being said, teachers need to create an environment where their bilingual and multilingual students feel welcome and comfortable in order to foster a positive relationship and community in the classroom. Teachers that are culturally sensitive seem to form better relationships with their students and create a curriculum that accommodates the students, rather than making it unnecessarily difficult for them (Olvera, 2015). Additionally, students succeed from being in an additive bilingual program or having the opportunity to be with students like them (Olvera, 2015). It is also essential that teachers encourage peer and social relations in their classroom. This can create opportunities for social interaction, conversational speech, and the development of a safe environment for students (Tran, 2015). These extra resources and opportunities are vital for the success of bilingual and multilingual students if available and accessible. All of these factors contribute to the integration of bilingual and multilingual students in the classroom and further ensure their academic success.

\section{SLP Preparedness}

SLP preparedness is limited when working with bilingual and multilingual students. It is essential to see SLPs in terms of preparedness and the feeling of competency as they are working on language and acquisition. Due to the diversity in our society, it is necessary for SLPs to receive coursework and continued professional development on working with diverse backgrounds. In one study, SLPs explained that there was a need for this continued education while treating clients with limited English proficiency; however, it is not easy to receive due to the lack of time and availability of professional development (Santhanam \& Parveen, 2018). Hammer, Detwiler, Detwiler, Blood and Qualls (2004) found that in addition to the lack of continued professional education many SLPs explained that they received limited or no coursework regarding bilingual and multilingual clients while in undergraduate and graduate school. Furthermore, they mentioned that with the lack of information for SLPs available, many lack self-confidence in working with the bilingual and multilingual population as it is not something they have much prior knowledge about). SLPs may feel as if they are not prepared for working with this population, given the lack of resources and prior research.

On the other end, SLPs who have received training in working with ELL patients explained that they did feel more competent in working with the bilingual and multilingual population. Additionally, these individuals found that they had many more individuals who were bilingual and multilingual in their practice compared to SLPs with limited training (Santhanam \& Parveen, 2018). In order to work with the bilingual and multilingual population, it is beneficial 
for the SLP to have taken a full course in bilingualism and bilingual education in order to have the needed preparation for working with these students (Hammond, Mitchell \& Johnson 2009). Although there is a range in coursework and professional development, it is a necessary component in order to ensure the success of both the SLP and the child.

Due to this lack of research, many SLPs feel as if their academic and clinical training left them inadequately prepared for the assessment and treatment of bilingual students. SLPs feel as if there is not enough guidance when it comes to treatment decisions available for the individuals that they work with (Faroqi-Shah, Frymark, Mullen, \& Wang, 2010). This leads to difficulties in providing treatment and therapy options as they are unknown to the SLPs based on their limited background knowledge as well as lack of resources and assessments that can be used for each specific child (Teo, Brebner, McAllister, 2018).

\section{Diagnosing and Treating Bilingual Students}

When it comes to diagnosing and treating a bilingual student with a speech disorder, SLPs need to be aware of the fact that these individuals need guidance and support regarding all of the languages that they may speak. In bilingual and multilingual students, more than one language can greatly impact production and acquisition in terms of comprehension, communication, and fluency (Krulatz, 2016). As stated by Santhanam \& Parveen (2018), it is essential for SLPs to pay close attention to and take the necessary steps to diagnose and evaluate students, since there should be an evaluation done in their first language (L1). Additionally, they suggest that federal and state laws mandate that all non-English speaking clients should be both treated and evaluated in their L1 as well as that the assessment should be in the language of choice. Although this is a mandate, the lack of bilingual and multilingual SLPs creates a situation where many families have lack of information and communication due to the initial language barrier. Given this, when the SLP and client/ student speak the same language, there is a greater probability of more success as there is a greater ability to work and communicate with these students (Parveen \& Santhanam, 2020).

When it comes to treatment, SLPs must remember that they are working with students who speak more than one language and have different backgrounds and cultures. With this in mind, when creating a therapy plan for bilingual individuals with a speech disorder, it is important to recognize social, emotional, cultural, and cognitive reasons as well as motivation (Faroqi-Shah, Frymark, Mullen, \& Wang, 2012). SLPs may believe that students are unmotivated to work on speaking in their L2; however, many times this is not the case. It has been found that students are less willing to talk and collaborate when they cannot relate to, or communicate entirely with, their provider (Parveen \& Santhanam, 2020). These aspects play an essential role in the diagnosis process as well as in the therapy provided to students. During the diagnosis process, "it is necessary (a) to carefully select pictorial stimuli according to the person's cultural background and (b) to select verbal stimuli that tap into the same language processes across languages" (Ansaldo, Marcotte, Scherer, \& Raboyeau, 2008, p. 549). Given this, students may be more likely to want to speak their L1 over their L2 due to accessibility of the language and a higher level of confidence; however, it is essential to encourage and take into account the student's willingness to participate and talk in either language during therapy.

The preparedness and perceptions of educators and SLPs in the United States impacts the quality of the educational experiences of bilingual and multilingual students. In this study we will be examining the ways in which the level of preparedness of teachers and SLPs affects their perceptions of the students with whom they work. Within this we are looking into SLP perceptions of working with bilingual and multilingual students and how that compares to teachers' perceptions of this population. In this study, we will strive to answer the following question: How does preparedness affect teachers and SLPSs perceptions of working with bilingual and multilingual students compared to their monolingual peers? 


\section{Methods}

The purpose of this study is to examine the perceptions that teachers and SLPs hold regarding working with bilingual and multilingual students and the ways in which that impacts the educational experience of those students. Research has been conducted regarding teachers' perceptions of working with bilingual and multilingual students; however, there is a lack of research on SLPs and their perceptions of working with this population. Data has shown that teachers and SLPs may have negative perceptions of these students due to the lack of preparedness in coursework and continued professional development provided to these educators. Data has been collected about teachers and SLPs demographics, personal beliefs, how their behavior may change depending on whether they are working with bilingual students or non-bilingual students, and attitudes they may have towards working with students who speak English as a second/home language.

\section{Participants}

Participants in this study included 28 Speech Language Pathologists and 22 teachers in the United States. Participants consisted of five men and 45 women. Participants were between the ages of 26 and $71(M=42.2, S D=12.4)$ and were certified as a teacher or an SLP between 1 and 46 years $(M=15.4, S D=11.5)$. The degrees that participants obtained ranged from Bachelors to Doctorate. Participants worked in the following settings: six in private practices, 34 in public schools, six in other, 16 suburban, 20 urban, and zero rural. The majority of participants, 29, were monolingual, 15 were bilingual, and six were multilingual. The languages that participants spoke include English, Spanish, Korean, Mandarin, French, Italian, Yiddish, Kurdu, Hindi, Russian, Polish, and Greek. Participants were recruited by having publicly accessible emails to which they were sent a Qualtrics Survey requesting for participation in the study. In the email, we encouraged participants to share the survey with others who may be interested in participating.

\section{Materials and Procedure}

Participants received an email with a survey that asked them about their perceptions of working with bilingual students. (See Appendix A and B) This included demographic questions including the following: age, gender, years certified as a teacher or SLP, highest degree attained, work setting, whether or not they are bilingual, which languages they spoke if they were bilingual, how many courses they have taken, overall perceptions of bilingual and multilingual students compared to monolingual students, and the diagnostic and treatment process. In addition to this, participants were asked questions regarding their preparedness in learning to work with bilingual and multilingual students. Participants were asked their perceptions of bilingual and multilingual students compared to monolingual students. After the survey, the participants were given a page for the debriefing of the survey.

\section{Data Analysis}

Data was collected on Qualtrics and tests were run using the Jamovi software. Descriptive statistics were run in order to see demographic information about participants. An independent sample t-test was run to see the relationship between teacher and SLP perceptions of working with monolingual, bilingual, and multilingual students. In addition to this, a correlation matrix was run to determine if there was a relationship between the number of courses taken and the perceptions of working with bilingual students and how prepared the teachers and SLPs felt to work with the bilingual and multilingual population. (See Appendix C.) 


\section{Results}

We hypothesized that there would be a difference between teacher and SLP perceptions of working with bilingual and multilingual students versus with monolingual students. An independent sample t-test was run to see the relationship between teacher and SLP perceptions and results were significant. Results from a Likert scale showed that there was a significant difference between teachers and SLPs and the extent to which they agreed with the following statement: "I feel prepared to work with students who are bilingual" $(M=3.33, S D=1.15, p<.01)$. Additionally, results were significant regarding the responses to the following question: "Do you feel as if you can effectively communicate with all of the students in your class/ practice?" $(M=1.22, S D=.422, p<.05)$.

Table 1

Difference between SLPs and Teachers perspective.

\begin{tabular}{|c|c|c|c|c|c|c|c|c|}
\hline Item & Statistic & d & \multicolumn{2}{|c|}{$\mathrm{p}$ - value } & \multicolumn{2}{|l|}{ Cohen's d } & Mean & SD \\
\hline Effectively Communicate & e -2.75 & \multicolumn{2}{|c|}{34} & .010 & \multicolumn{2}{|l|}{-.940} & 1.22 & .422 \\
\hline \multirow[t]{2}{*}{ Prepared } & 2.00 & \multicolumn{2}{|c|}{46} & .004 & \multicolumn{2}{|l|}{.872} & 3.33 & 1.15 \\
\hline & Group & $\mathrm{N}$ & Mean & Median & SD & & SE & \\
\hline \multirow[t]{2}{*}{ Effectively Communicate } & SLP & 14 & 1.00 & 1.00 & 0.000 & 0.000 & & \\
\hline & Teacher & 22 & 1.36 & 1.00 & 0.492 & 0.105 & & \\
\hline \multirow[t]{2}{*}{ Prepared } & SLP & 27 & 3.74 & 4.00 & 0.944 & 0.182 & & \\
\hline & Teacher & 21 & 2.81 & 2.00 & 1.209 & 0.264 & & \\
\hline
\end{tabular}

We hypothesized that there would be a difference in the perceptions that monolingual teachers and SLPs hold as compared to bilingual or multilingual teachers and SLPs. An independent sample t-test was run to see the difference between monolingual teachers and SLPs compared to bilingual/multilingual teachers and SLP perceptions. Results from a student t-test showed that there was a significant difference between monolingual SLPs and teachers compared to bilingual and multilingual SLPs and teachers when it came to responses to the following: "I feel prepared to work with students who are bilingual" $(M=3.3, S D=1.15, p<.05, d>.8)$ and "It is easy to work with students in more than one language" $(M=2.8, S D=1.22, p<.01, d>.8)$.

Table 2

Difference between monolingual and bilingual/multilingual SLPs and Teachers perspective.

\begin{tabular}{|c|c|c|c|c|c|c|c|}
\hline Item & Statistic & $\mathrm{df}$ & $\mathrm{p}$ - value & & Cohen's d & Mean & $\mathrm{SD}$ \\
\hline Prepared & -2.75 & 34 & .010 & & -.940 & 3.33 & 1.15 \\
\hline \multirow[t]{2}{*}{ Easy Work } & 2.00 & 46 & .004 & & .872 & 2.80 & 1.22 \\
\hline & Group & $\mathrm{N}$ & Mean & Median & SD & & \\
\hline
\end{tabular}




\begin{tabular}{c|cccccc} 
Prepared & Monolingual & 29 & 3.76 & 4.00 & 0.988 & 0.183 \\
& \multirow{2}{*}{ Bilingual/ Multilingual } & 19 & 2.68 & 2.00 & 1.108 & 0.254 \\
Easy Work & Monolingual & 30 & 3.13 & 3.00 & 1.252 & 0.229 \\
& Bilingual/ Multilingual & 16 & 2.19 & 2.00 & 0.911 & 0.228 \\
\hline
\end{tabular}

We hypothesized that there was going to be a relationship between the number of courses taken and the level of preparedness for teachers and SLPs. We ran a Pearson correlation and found that there was a significant positive relationship between the number of courses taken and the extent to which teachers and SLPs felt prepared to work with bilingual and multilingual students $(p<.001)$. Showing that teachers and SLPs who had taken more coursework felt more prepared to teach bilingual students. In addition to this, we found a positive relationship between teachers and SLPs feeling prepared and feeling as if it is easy to work with bilingual and multilingual students $(p<.001)$. Additionally, we found a positive relationship between teachers and SLPs feeling prepared and feeling able to diagnose students who are bilingual and multilingual with a learning disability $(p<.05)$ and a speech disorder $(p<.001)$.

Table 3

Correlations between SLPs and Teachers perceptions.

\begin{tabular}{|c|c|c|c|c|c|c|}
\hline & & Courses & Prepared & Easy Work & Diagnosed SD & Diagnosed LD \\
\hline \multirow[t]{2}{*}{ Courses } & Pearson's r & & & & & \\
\hline & p-value & & & & & \\
\hline \multirow[t]{2}{*}{ Prepared } & Pearson's r & .524 & & & & \\
\hline & $\mathrm{p}$-value & $<.001$ & & & & \\
\hline \multirow[t]{2}{*}{ Easy Work } & Pearson's r & .385 & .563 & & & \\
\hline & P-value & .013 & $<.001$ & & & \\
\hline \multirow[t]{2}{*}{ Diagnosed SD } & Pearson's r & .220 & .519 & .630 & & \\
\hline & p-value & .161 & $<.001$ & $<.001$ & & \\
\hline \multirow[t]{2}{*}{ Diagnosed LD } & Pearson's r & .119 & .368 & .444 & .685 & \\
\hline & $\mathrm{p}$-value & .547 & .038 & .014 & $<.001$ & \\
\hline
\end{tabular}

We ran a correlation matrix and found that there was a significant negative relationship between the idea that "monolingual and bilingual/multilingual students can be treated the same way" and that it is difficult to work with students who are bilingual or multilingual $(p<.001)$. This shows that bilingual students may need accommodations; however, they may require more work and training in order for it to be successful and for the individual to feel as if it is not difficult to work with the student. Finally, there was a negative relationship between the idea that there are many obstacles when working with a student who is bilingual and that the teacher or SLP can change their teaching style depending on if they are teaching monolingual or bilingual students $(p<.05)$. This result explains that the more obstacles a teacher or SLP believes that there are when working with bilingual students, the less likely they are to change 
their teaching style (including accommodations or resources), resulting in a negative relationship between the student and the teacher or SLP.

Table 4

Correlations between SLPs and Teachers perceptions.

\begin{tabular}{|c|c|c|c|c|}
\hline & & MBTreatment & Difficult & Obstacles \\
\hline MBTreatment & $\begin{array}{l}\text { Pearson's r } \\
\text { p-value }\end{array}$ & & & \\
\hline Difficult & $\begin{array}{l}\text { Pearson's r } \\
\text { p-value }\end{array}$ & $\begin{array}{l}.419 \\
<.01\end{array}$ & & \\
\hline Obstacles & $\begin{array}{l}\text { Pearson's r } \\
\text { p-value }\end{array}$ & $\begin{array}{c}.494 \\
<.001\end{array}$ & $\begin{array}{r}.739 \\
<.001\end{array}$ & \\
\hline
\end{tabular}

\section{Discussion}

Based on our research, we found that there was a difference in the way monolingual teachers and SLPs perceived working with bilingual and multilingual students compared to the bilingual and multilingual teachers and SLPs. That being said, the lack of resources available to these professionals who work with this population is alarming. Monolingual SLPs and teachers feel unprepared to work with bilingual and multilingual students and like they cannot effectively communicate with their students. An increase in the number of bilingual and multilingual SLPs and teachers would likely improve the experiences of bilingual and multilingual students.

Similarly to what Umansky and Dumont (2019) found, everyone holds certain perceptions about any given topic whether they choose to recognize it or not. This further emphasizes the importance of a substantial, thorough training in undergraduate and graduate programs. If these professionals do not get proper training in which they analyze and question their own beliefs, then how can they be expected and trusted to effectively work with and accommodate all students? We talk about the importance of the educational experience of students, and the educational experience of SLPs and teachers in preparing to work with these students is no less important. As found by Palmer and Martinez (2013) it is often a challenge to inform current approaches to teacher preparation however it is necessary in order to understand how to work more effectively with this population. These experiences, particularly the quality of each, will directly affect each other.

In our research we found that there was limited coursework available for SLPs and teachers when preparing to work with bilingual and multilingual students. $(M=2.36, S D=1.80)$. Within this, many of the SLPs expressed that in their work, they did not feel fully prepared to identify specific language impairments. Given their lack of coursework, educators often question their ability to effectively work with this population as they feel unqualified due to their lack of training. On the other hand, some participants with little to no preparedness in terms of the amount of courses taken, felt prepared to work with bilingual students. The problem is that they reported feeling prepared despite having little to no formal training in their own schooling to work with these students. Some reported feeling prepared after having taken only one course that was designed to help them prepare to work with bilingual students. After reviewing this data, we realized how much ambiguity there is in trying to define preparedness. We found this level of ambiguity concerning, especially considering what it reveals in thinking about the following question: what defines preparedness? 


\section{Limitations}

As with all research, the present study has limitations. Limitations in this study included a lack of male participants as well as no rural participants. Given this lack of gender and geographical diversity, it makes it hard to generalize our findings with regard to these specific populations. Additionally, we had a small sample size and an unbalanced number between bilingual and monolingual participants. However, despite that, we can still draw some conclusions based on our findings. With these limitations, more research will need to be done in order to make more precise claims regarding those more specific populations.

\section{Conclusion}

Overall, we found that teachers and SLPs that are bilingual and multilingual hold different perceptions than their monolingual counterparts. Additionally, there is evidence that both teachers and SLPs want and need more coursework and professional development training on how to work with bilingual and multilingual students. Teachers and SLPs felt ill-prepared to work with students who are bilingual and multilingual. This may affect the academic success and emotional wellbeing of their students. Additionally, teachers and SLPs must feel confident enough to create curriculums and treatment plans that accommodate all students. Changing the curriculum and treatment options may be necessary when working with students who speak more than one language in order to best support them and help them succeed. It is necessary for educators to be aware of unknown biases that they may hold toward students.

\section{References}

Ansaldo, A. I., Marcotte, K., Scherer, L., \& Raboyeau, G. (2008). Language therapy and bilingual aphasia: Clinical implications of psycholinguistic and neuroimaging research. Journal of Neurolinguistics, 21(6), 539-557.

https://doi.org/10.1016/j.jneuroling.2008.02.001

Commins, N. L., \& Miramontes, O. B. (1989). Perceived and actual linguistic competence: A descriptive study of Four Low-Achieving Hispanic bilingual students. American Educational Research Journal, 26, 443472.https://doi.org/10.3102/000283120 26004443

De Lamo White, C., \& Jin, L. (2011). Evaluation of speech and language assessment approaches with bilingual children. International Journal of Language and Communication Disorders, 46(6), 613-627. https://doi.org/10.1111/j.1460-6984.2011.00049.x

Edl, H. M., Jones, M. H., \& Estell, D. B. (2008). Ethnicity and English proficiency: Teacher perceptions of academic and interpersonal competence in European American and Latino students. School Psychology Review, 37(1), $38-45$.

Faroqi-Shah, Y., Frymark, T., Mullen, R., \& Wang, B. (2010). Effect of treatment for bilingual individuals with aphasia: A systematic review of the evidence. Journal of Neurolinguistics, 23(4), 319-341.

https://doi.org/10.1016/j.jneuroling.2010.01.002

Fitts, S., \& Gross, L. A. (2012). Teacher candidates learning from English Learners: Constructing concepts of language and culture in Tuesday's Tutors After-School Program. Teacher Education Quarterly, 39, 75-95. 
Hammer, C. S., Detwiler, J. S., Detwiler, J., Blood, G. W., \& Qualls, C. D. (2004). Speech-language pathologists' training and confidence in serving Spanish-English Bilingual children. Journal of Communication Disorders, 37(2), 91-108. https://doi.org/10.1016/j.jcomdis.2003.07.002

Hammond, C., Mitchell, P., \& Johnson, M. (2009). Academic and Clinical Preparation for Cultural and Linguistic Diversity in Speech-Language Pathology: Program Director Perspectives. Contemporary Issues in Communication Science and Disorders,36(Spring), 63-76. https://doi.org/10.1044/cicsd 36 S 63

Han, W. (2012). Bilingualism and academic achievement. Published by : Wiley on behalf of the Society for Research in Child Development. Society for Research in Child Development, 83(1), 300-321.

Krulatz, A., \& Dahl, A. (2016). Baseline assessment of Norwegian EFL teacher preparedness to work with multilingual students. Journal of Linguistics and Language Teaching, 7(2), 199-218. https://sites.google.com/site/linguisticsandlanguageteaching/home-1/volume-7-2016-issue-2/volume-7-2016-issue-2---article-krulatz-dahl

MacIntosh, R., \& Ornstein, J. (1974). A brief sampling of West Texas teacher attitudes toward Southwest Spanish and English Language varieties. American Association of Teachers of Spanish and Portuguese 57(4), 920-926.

Olvera, C. (2015). Teacher perceptions of English learners acquisition of academic English: Impacts on long term English learner classification. EJournal of Education Policy spec is, 78-92.

Palmer, D., \& Martínez, R. A. (2013). Teacher agency in bilingual spaces: A fresh look at preparing teachers to educate Latina/o bilingual children. Review of Research in Education, 37, 269-297. https://doi.org/10.3102/0091732X12463556

Parveen, S., \& Santhanam, S. priya. (2020). Speech-Language Pathologists' Perceived Competence in Working With Culturally and Linguistically Diverse Clients in the United States. Communication Disorders Quarterly. https://doi.org/10.1177/1525740120915205

Pérez Cañado, M. L. (2016). Teacher training needs for bilingual education: in-service teacher perceptions. International Journal of Bilingual Education and Bilingualism, 19(3), 266-295.

https://doi.org/10.1080/13670050.2014.980778

Rizzuto, K. (2017). Teachers' Perceptions of ELL Students: Do Their Attitudes Shape Their Instruction? Teacher Educator, 52(3), 182-202. https://doi.org/10.1080/08878730.2017.1296912

Santhanam, S. P., \& Parveen, S. (2018). Serving culturally and linguistically diverse clients: A review of changing trends in speech-language pathologists' self-efficacy and implications for stakeholders. Clinical Archives of Communication Disorders, 3(3), 165-177. https://doi.org/10.21849/cacd.2018.00395

Teoh, W. Q., Brebner, C., \& McAllister, S. (2018). Bilingual assessment practices: challenges faced by speech-language pathologists working with a predominantly bilingual population. Speech, Language and Hearing, 21(1), 1021. https://doi.org/10.1080/2050571X.2017.1309788

Tran, Y. (2015). ESL Pedagogy and Certification: Teacher Perceptions and Efficacy. Journal of Education and Learning, 4(2). https://doi.org/10.5539/jel.v4n2p28 
Umansky, I., \& Dumont, H. (2019). English Learner Labeling: How English Learner Status Shapes Teacher Perceptions of Student Skills \& the Moderating Role of Bilingual Instructional Settings. EdWorking Paper, 19, 19-94. http://www.edworkingpapers.com/ai19-94 